\title{
An Overview of Social Aspects of COVID-19 Pandemic
}

\author{
Sarita Gautam
}

Assistant Professor, Department of Social Sciences, NIHFW, New Delhi

\begin{abstract}
COVID-19 pandemic is more than a health crisis. It is a human, economic and social crisis. As a pandemic, it is attacking societies at their core. ${ }^{1}$ Many changes and challenges are developing in the society during the COVID-19 pandemic. The aim of this paper is to describe and analyze the COVID19 pandemic situation in the social context. This paper deals with association of COVID-19 genesis and globalization, phase of involuntary immobility due to lockdown, sick role of COVID-19 patient, social stigma associated with COVID-19 patient, new behavioral norms to reduce the transmission of corona virus and the importance of community participation to combat this pandemic and prepare for the future. A lesson can be learned from this pandemic situation that implementation of all precautionary social measures effectively and construction of social support system strong collectively are very important tools to reduce damage from COVID-19 like public health crisis. Community involvement can drive every citizen to be aware about transmission of corona virus and practice of all precautionary measures to prevent from COVID19 virus.
\end{abstract}

Keywords: COVID-19 pandemic, corona virus, social aspects, health crisis

\section{INTRODUCTION}

We are living in a 'risk society' where no one can predict the coming unknown risks and dangers. The world is facing the crisis of COVID-19 pandemic, which is the result of transmission of corona virus from an infected person to another person. The emergence of this virus infection is from Wuhan, China on December 2019. Due to population mobility this virus spreads into many countries. The potential for spread of infectious diseases has been significantly enhanced in today's world by the globalization of trade and travel.2

Human mobility is the part of civilization and very significant expression of the interrelationship. The transformation in the human mobility developed between the end of the twentieth century and the beginning of the twenty first in the context of advanced globalization. Through the process of globalization we are sharing ideas, technologies, skills, goods and services, opportunities and finance with other countries now we have shared the virus. COVID-19 pandemic has changed the pattern of behavior and ways of living in the society. The current situation also generates new social challenges and effects on people.

The aim of this paper is to highlight and analyze the social aspects and social issues, aroused during and after this COVID-19 pandemic.

Phase of Involuntary Immobility: Human mobilization is an important part of social life. This is a new and changing face of our social system that we are shifting from voluntary mobility to involuntary immobility. In this public health crisis, we are living in the age of involuntary immobility for many days to prevent the spread of infection. Government has implemented the nationwide lockdown to limit the mobility of people to control the 
infection of corona virus for the welfare of society. This lockdown includes of schools and business, geographical areas quarantine and restriction of international travel also.

The consequences of involuntary immobility are different for people of different social gradient. Condition of a person of upper class and middle class is different from lower class. Upper and middle class are facing the immobility in a house with family and digitally connected with colleagues, friends and relatives worldwide. They are suffering from mental distress result of isolation. On the other hand, for poor people or daily wagers this is the time of very hardship and matter of survival.

Sick Role of COVID-19 patients: An American sociologist, Talcott Parsons has given the concept of the sick role which describes the patterns of behaviour which the sick person adopts in order to minimise the disruptive impact of illness on others. Parsons argued that being sick means the sufferer enters a role of 'sanctioned deviance'. ${ }^{3}$

Main aspects of concept of the sick role: -

1. The sick person exempts from normal social roles and responsibilities. This exemption is relative to the nature and severity of illness. Exemptions require legitimating by the doctor as the authority.

2. The sick person is not responsible for his or her condition. Illness is seen as the result of physical causes beyond the individual's control.

3. The sick person should try to get well.

4. The sick person should seek technically competent help and cooperate with the doctor in the process of trying to get well.

The situation of corona crisis also exemplifies the concept of sick role.

A corona suspected or infected person is exempted from any kind of his regular social role and work responsibility. Government has advised to installed an AAROGYA setu app on mobile of every citizen for regular self assessment. The user of this app is asked some question designed to assess him about corona symptoms. In case some of the answers suggest COVID19symptoms, the information will be sent to a government server. This process will help government to take timely steps. A user will be alerted if someone came in close proximity with him, unknowingly and tests positive. If a person realizes any kind of symptoms or conditions after assessment may get in self isolation.

As a contagious disease COVID-19 a person got infected inadvertently from symptomatic and asymptomatic people infected corona virus, hence patient is not responsible for the situation. Only awareness and precautions can prevent to spread the transmission of corona virus from infected to uninfected person. The mode of transmission of corona virus is respiratory droplets. Droplet transmission occurs when a person is in close contact (within $1 \mathrm{~m}$ ) with someone who has respiratory symptoms (e.g., coughing or sneezing) and is therefore at risk of having his/her mucosae (mouth and nose) or conjunctive (eyes) exposed to potentially infective respiratory droplets. Transmission may also occur through fomites in the immediate environment around the infected person. ${ }^{4}$

Hence the probability of corona virus transmission is by direct contact with infected person and indirect contact with surfaces in the immediate environment or objects used on the infected person.

Airborne transmission is different from droplet transmission as it refers to the presence of microbes within droplet nuclei, which are generally considered to be particles $<5 \mu \mathrm{m}$ in diameter, can remain in the air for long periods of time and be transmitted to others over distances greater than $1 \mathrm{~m}^{5}$

Taking measures to preventing spread the corona virus is a social responsibility of all members of community. Being a part of a community, this is social responsibility of corona virus infected 
person that not to make other people of infected and sick.

A person who is suffering from any kind of very mild corona virus infection symptoms should first stay in self isolation at home but avoid the contacts with other family members and monitor the symptoms. If the symptoms get sever then it is important after that he should seek medical treatment to get well and inform the government helpline number for help or any other medical provider. A person develops emergency warning signs for COVID-19 get medical attention immediately. Emergency warning signs include:

- Trouble breathing

- Persisting pain or pressure in the chest

- New confusion or inability to arouse

- Bluish

Social stigma associated with COVID-19: Social stigma is a significant hurdle of health seeking behavior in case of many health conditions and diseases. A sociologist Erving Goffman described that stigma is a relationship of devaluation in which one individual is disqualified from full social acceptance. $^{6}$

Social stigma influences population health outcomes by worsening, undermining or impeding a number of processes, including social relationships, resource availability, stress and psychological and behavioral responses, exacerbating poor health . ${ }^{7}$

In Indian society, patients of many infectious diseases, illness and health conditions including leprosy, epilepsy, TB, HIV, mental health, cancer, are facing social stigma. These patients are coping with double burden, first with adverse physical condition and second with mental trauma result of social stigma.

"Social stigma in the context of health is the negative association between a person or group of people who share certain characteristics and specific disease. In an outbreak this may mean people are labelled, stereotyped, discriminated against, treated separately, and /or experience loss of status because of a perceived link with a disease." Such treatment can negatively affect those with the disease, as well as their caregivers, family, friends and communities. The current COVID-19 outbreak social stigma and discriminatory behaviors against people of certain ethnic backgrounds as well as anyone perceived to have been in contact with the virus. ${ }^{8}$

The level of stigma associated with COVID19 is based on three main factors:

1. It is a disease that's new and for which there are still many unknowns

2. We are often afraid of the unknown: and

3. It is easy to associate that fear with 'others'.

Three major impacts of social stigma are:

1. Drive people to hide the illness to avoid discrimination

2. Prevent people from seeking health care immediately

3. Discourage them from healthy behaviors

In the current context in India, due to fear of social stigma many patients who have COVID-19 like symptoms are bound to hide their health conditions and not seeking for health care facilities for treatment that is actually causing an increase in morbidity and mortality.

Stigma can weaken social cohesion and incite social isolation of person or groups, which might be promote the spread of virus. This situation can result in difficulties in controlling and managing this disease outbreak.

We can address the social stigma by correcting misconceptions, breaking rumours and sharing accurate information about COVID-19. Using appropriate words and avoiding negative attitude during the treatment of COVID-19 patients.

New social and behavioral norms: According to the sociologist MacIver and Page changes occurs in the biological and physical world that beyond the human control influences the human social behavior. The changes happen because of human activity. 
To combat the COVID-19 WHO has advised the people to adopt some public health and social measures. The public health and social measure include personal protective measures (hand hygiene, respiratory etiquette), environmental measures, physical distancing measures and travel related measures. ${ }^{9}$

Now Social distancing, hand washing, wearing mask and maintain other hygiene habits are now become new social behaviors and behavioural norms and people have to be aware and internalized new norms to prevent COVID-19 infection. Among several COVID-19 initiatives promoting hand hygiene, the WHO "Save Lives : Clean Your Hands”(SLCYH) global campaign focuses on hand hygiene in health care and celebrated on $5^{\text {th }}$ May every year. Frequent and proper hand hygiene is one of the most important measures that can be used to prevent infection with COVID-19 virus. Community members can play a critical role in fighting COVID-19 by adopting frequent hand hygiene as part of their day-to-day practices. As per this campaign guidelines wash hands with soap and running water when hands are visibly dirty, if hands are not visibly dirty, frequently clean them by using alcohol based hand rub or soap and water. Every person is advised to wash his/her hands

- after coughing or sneezing,

- when caring for the sick,

- before, during and after you prepare food,

- before eating

- after toilets use

- when hands are visibly dirty

- after handling animals or animal waste Physical distancing (social distancing) means keeping at least 6 feet space between one person to other person outside of your home, even when both persons wear mask or any face covering. Any type of social, political and educational gathering should be avoided in this situation.
Wearing mask or covering face is also an important behavioural measure to prevent the transmission of COVID-19.

The provision of safe water, sanitation and hygienic conditions and waste management practices in communities, homes, schools, marketplace, and health facilities will help to protecting human health and prevent human to human transmission of COVID-19 virus and prevent other infectious disease. We should take this current public health crisis as an opportunity to internalize good hygiene and sanitation practices for preparedness of better future.

\section{Community participation during COVID-19 pandemic: Community} participation means involvement of people in a community in plans to solve their own problems. It is a social process in which groups with shared needs living in a specific geographical area actively identify their needs, make decision and set up mechanisms to achieve solutions. Community participation enhances social cohesion because communities be aware of the value of working in partnership with each other and with statutory agencies.

Global health guidelines emphasize the importance of community participation. ${ }^{10}$ Community participation is playing significant role in fighting with COVID-19 pandemic situation. Community participation is very essential in the collective response to COVID-19 pandemic, from compliance with lockdown, to the steps that need to be country ease restrictions, to community support through volunteering. Involvement of local leaders of community, local ideas and inputs from members of diverse groups to minimize the risk of COVID-19 can control the situation in particular locality. Community member, including vulnerable and marginalized groups can come together to control rumors, remove structural barriers and reduce social stigma.

In this uncertain situation society are undergoing rapid and far-reaching changes. This is very crucial time when social 
cohesion is needed to understand and fulfill the additional needs of vulnerable and marginalized people and lived experiences of difficulties caused by government restrictions. We know continuous lockdowns has increased the cases domestic violence. Right and access of contraception, abortion, pre- natal and safe child birth care is being undermined. Managing these special needs and care can be possible by responsible community members participation.

There is a requirement to set up and fund specific community engagement taskforce to ensure that community voice is incorporated into the pandemic response. Those who are working to address COVID19 in the health and social care sectors and beyond should look to existing community groups and networks to build coproduction. Authority should ensure every citizen understand that their voices are being heard. Every member of community should have believed that his/her wellbeing is valued and their needs addressed which in turn will help increase compliance with restrictions and encourage sharing of creative solutions. Like India, many countries, community members have created groups to distribute food and other essential items to help deprived people. Some NGOs and women self-help groups have prepared masks for poor people.

\section{CONCLUSION}

The COVID19 outbreak affects all segments of the population and is particularly destructive to members of those social groups in the most vulnerable situations, including poor people, older persons, persons with disabilities, youth and indigenous peoples. The lockdown affects people of every socio-economic class but more poor people are suffering. Laborers, homeless people, refuges, migrants or displaced persons also stand to suffer disproportionately both the pandemic and its aftermath whether due to unemployment. The social crisis created by pandemic may increase inequality, exclusion, discrimination, mass unemployment, violence, distress which may result suicide and crime in the medium and long term. ${ }^{11}$ Perhaps these days we are at the beginning of new phase of changes in our society. Our society marked by new challenges and uncertainties, but use should place a notion of trust in life. Social solidarity, social support and social protection policy are durable solution to the save the lives of poor people reduce the panic of corona virus. We must come together to save the lives of every member of society.

\section{Acknowledgement: None}

\section{Conflict of Interest: None}

\section{Source of Funding: None}

\section{REFERENCES}

1. Everyone included: Social impact of COVID19, (2020) Department of Economic and Social Affairs, retrieved from: http:// www.un.org/development/desa/dspd.

2. Cockerham, Geoffrey.B, and William C. Cockerham (2010) Health and Globalization. Cambridge, UK: Polity)

3. Prarsons, Totcott, (1991), The social system, Routledge, Toylor \& Francis, London, UK. ISBN -0-415-06055-9.

4. Ong SW, Tan YK, Chia PY, Lee TH, Ng OT, Wong MS, et al. Air, 2020, surface environmental, and personal protective equipment contamination by severe acute respiratory syndrome coronavirus 2 (SARS$\mathrm{CoV}-2$ ) from a symptomatic patient. JAMA. Mar 4 [Epub ahead of print].

5. Retrieved From https://www.who.int/newsroom/commentaries/detail/modes-oftransmission-of-virus-causing-covid-19implications-for-ipc-precautionrecommendations

6. Goffman E.,( 1963)Stigma: Notes on the Management of Spoiled Identity, New York : Simon \& Schuster,

7. Hatzenbuehler ML, Phelan JC, Link BG. (2013)Stigma as a Fundamental Cause of Population Health Inequalities, Am J Public Health :103 (5)813-21)

8. Social stigma associated with COVID-19 (2020) WHO, retrieved from : 
https://www.who.int/who-documentsdetail/a-guide-to-preventing-andaddressing-social-stigma-associated-withcovid19?gclid=EAIaIQobChMI947YwtbP6QIVQ 6qWCh0DPgXsEAAYASAAEgJzGfD_Bw $\mathrm{E}$

9. Considerations in adjusting public health and social measures in the context of COVID-19, 16 April 2020, Interim guidance, WHO

10. WHO. The global strategy for women's, children's and adolescent's health (2016-
2030) , Geneva , World health organization , 2015 .

11. Everyone included: Social impact of COVID19 , 2020, Department of Economic and Social Affairs, retrieved from: http:// www.un.org/development/desa/dspd.

How to cite this article: Gautam S. An overview of social aspects of COVID -19 pandemic. Int $J$ Health Sci Res. 2021; 11(12):59-64. DOI: https://doi.org/10.52403/ijhsr.20211209 